\title{
Stenotrophomonas comparative genomics reveals genes and functions that differentiate beneficial and pathogenic bacteria
}

Peyman Alavi ${ }^{1 *}$, Margaret R Starcher ${ }^{1}$, Gerhard G Thallinger ${ }^{2}$, Christin Zachow ${ }^{2}$, Henry Müller $^{1}$ and Gabriele Berg ${ }^{1}$

\begin{abstract}
Background: In recent years, the number of human infections caused by opportunistic pathogens has increased dramatically. Plant rhizospheres are one of the most typical natural reservoirs for these pathogens but they also represent a great source for beneficial microbes with potential for biotechnological applications. However, understanding the natural variation and possible differences between pathogens and beneficials is the main challenge in furthering these possibilities. The genus Stenotrophomonas contains representatives found to be associated with human and plant host.
\end{abstract}

Results: We used comparative genomics as well as transcriptomic and physiological approaches to detect significant borders between the Stenotrophomonas strains: the multi-drug resistant pathogenic S. maltophilia and the plant-associated strains S. maltophilia R551-3 and S. rhizophila DSM14405 (both are biocontrol agents). We found an overall high degree of sequence similarity between the genomes of all three strains. Despite the notable similarity in potential factors responsible for host invasion and antibiotic resistance, other factors including several crucial virulence factors and heat shock proteins were absent in the plant-associated DSM $14405^{\top}$. Instead, S. rhizophila DSM14405 ${ }^{\top}$ possessed unique genes for the synthesis and transport of the plant-protective spermidine, plant cell-wall degrading enzymes, and high salinity tolerance. Moreover, the presence or absence of bacterial growth at $37^{\circ} \mathrm{C}$ was identified as a very simple method in differentiating between pathogenic and non-pathogenic isolates. DSM $14405^{\top}$ is not able to grow at this human-relevant temperature, most likely in great part due to the absence of heat shock genes and perhaps also because of the up-regulation at increased temperatures of several genes involved in a suicide mechanism.

Conclusions: While this study is important for understanding the mechanisms behind the emerging pattern of infectious diseases, it is, to our knowledge, the first of its kind to assess the risk of beneficial strains for biotechnological applications. We identified certain traits typical of pathogens such as growth at the human body temperature together with the production of heat shock proteins as opposed to a temperature-regulated suicide system that is harnessed by beneficials.

Keywords: Human pathogens, Stress Protecting Agent (SPA), Genomics, Transcriptomics

\section{Background}

During the last years, the number of human infections caused by opportunistic pathogens has increased dramatically. One natural reservoir of opportunistic pathogens is the rhizosphere, the zone around roots that is influenced by the plant $[1,2]$. Due to a high content of

\footnotetext{
* Correspondence: alavi@tugraz.at

${ }^{1}$ Graz University of Technology; Environmental Biotechnology, Petersgasse

12, 8010 Graz, Austria

Full list of author information is available at the end of the article
}

nutrients, this habitat is a 'microbial hot-spot', where bacterial abundances including those with strong antagonistic traits are enhanced [3]. Various bacterial genera, including Burkholderia, Enterobacter, Herbaspirillum, Ochrobactrum, Pseudomonas, Ralstonia, Staphylococcus and Stenotrophomonas, contain root-associated strains that can encounter bivalent interactions with both plant and human hosts [2]. Mechanisms responsible for colonization of the rhizosphere and antagonistic activity 
against plant pathogens are similar to those responsible for colonization of human organs and tissues, and pathogenicity [2]. Multiple resistances against antibiotics are not only found with clinical strains but also with strains isolated from the rhizosphere [4]. High competition, the occurrence of diverse antibiotics and secondary antimicrobial plant metabolites, and enhanced horizontal gene transfer and mutation rates in this microenvironment contribute to the high levels of natural resistances [5]. On the other hand, rhizosphere inhabitants have an enormous potential as biocontrol or stress protecting agents or as fertilizers for sustainable agriculture [6,7].

Stenotrophomonas maltophilia is an emerging global pathogen and already one of the most common opportunistic pathogens in hospitals $[8,9]$. A recent study shows that approx. $5 \%$ of the Gram-negative infections were caused by $S$. maltophilia in intensive care units in the United States. The two most common diseases caused by S. maltophilia are bacteremia and pneumonia, which are often associated with high mortality rates. S. maltophilia strains are characterized by multi-resistance to many antibiotics [10]. For a long time it was not possible to differentiate between the clinical and environmental S. maltophilia strains [4]. Using a polyphasic approach, Wolf et al. [11] were able to describe a new plant-associated species within the $S$. maltophilia complex. Interestingly, no human-pathogenic potential has ever been observed in this phylogenetically and ecologically closely related species [11]. Moreover, both species can be easily distinguished with regard to the production of the osmoprotective substance glucosylglycerol (only present in S. rhizophila) and the occurrence of specific multidrug-efflux pumps (only present in S. maltophilia) [12]. S. rhizophila is both rhizosphere- and phylloplane- competent and shows pronounced salt tolerance, and is hence a model bacterium among the plant growth-promoting rhizobacteria (PGPR) [13]. Plant growth promotion by S. rhizophila strain DSM14405 ${ }^{\mathrm{T}}$ (syn. strain e-p10) was observed under greenhouse conditions [14] and in the highly salinated soils of Uzbekistan at levels up to $180 \%$ [15]. However, S. maltophilia was a typical rhizosphere bacterium used as an efficient biocontrol agent, and until the 1980s, no capacity to cause infection had ever been reported. Now, the theory is established that the ancestors of virulent bacteria including Stenotrophomonas, as well as the origin of virulence and resistance determinants, lay most likely in the environmental microbiota [5]. It is now one of the main challenges to predict any risk for human health [16]. Currently, these potential risk factors are a main obstacle in registration procedures, especially in the European Union [17]. Next generation sequencing and the corresponding bioinformatic analyses have an enormous impact on our understanding of microbial communities and the host-microbe interactions $[18,19]$. However, is it possible to use these techniques to solve this problem?
The objective of our study was to find out if there is a borderline based on the distinguishing features between the beneficials and pathogens within the genus Stenotrophomonas. Moreover, using genomics, transcriptomics and physiological assays, we try to predict the potential risk of the stress protecting agent $S$. rhizophila strain DSM $14405^{\mathrm{T}}$ for humans by studying its genetic potentials and comparing these with two Stenotrophomonas model strains, the human-pathogenic S. maltophilia K279a [20] and the plant-associated S. maltophilia R551-3 [21].

\section{Results \\ Comparisons of plant and human-associated Stenotrophomonas genomes}

General genomic features of S. rhizophila DSM14405 ${ }^{\mathrm{T}}$ were compared to the plant-associated $S$. maltophilia R551-3 and the human pathogenic S. maltophilia K279a (Table 1). The genome of S. rhizophila DSM $14405^{\mathrm{T}}$ consists of 4,648,976 nucleotides with a GC content of $67.26 \%$, and has been predicted to code for 4,033 CDSs. Compared with S. maltophilia R551-3 and S. maltophilia K279a with each 4,573,969 n (4,039 CDSs) and 4,851,126 n (4,386 CDSs), respectively, the size of the genome and the predicted number of CDSs are slightly smaller. There is no plasmid present in S. rhizophila DSM $14405^{\mathrm{T}}$.

Figure 1 shows genomic comparisons between the genome of S. rhizophila DSM $14405^{\mathrm{T}}$, S. maltophilia R551-3 [21] and S. maltophilia K279a [20]. Overall, there is a very high degree of sequence similarity between the genome of the plant growth-promoting S. rhizophila and both $S$. maltophilia R551-3 and the humanpathogenic K279a. The homology boxes are however separated by non-homologous regions. The whole genome sequence comparison between the three genomes was also performed using the Artemis Comparison Tool (ACT) which revealed the same result as in Figure 1 and is presented in Additional file 1: Figure S1. Figure 2 represents circular genomic map of S. rhizophila DSM $14405^{\mathrm{T}}$, wherein DNA coordinates are presented and coding sequences (CDSs) on both the leading and lagging strands are assigned colors with respect to functional gene groups. In addition, the figure depicts the position of tRNA and rRNA genes, and other characteristics of the S. rhizophila DSM14405 ${ }^{\mathrm{T}}$ genome such as GC content as well as the excess of $C$ over $G$ throughout the whole genome (GC skew) with the regions above and below average shown in different colors. Furthermore, gene orthology analyses were performed, in which $S$. rhizophila genes were compared with those of S. maltophilia R551-3 and K279a to detect orthologous genes shared among strains (Figure 3). In addition to orthologous genes, Figure 3 depicts the position and color-coded function of the S. rhizophila DSM14405 ${ }^{\mathrm{T}}$-specific genes. The numbers of orthologous and strain-specific unique genes are shown in the Venn 
Table 1 General genomic characteristics of S. rhizophila DSM14405 ${ }^{\top}$, S. maltophilia R551-3 and S. maltophilia K279a

\begin{tabular}{lccc}
\hline & S. rhizophila DSM $\mathbf{~ 1 4 4 0 5 ~}^{\mathbf{T} *}$ & S. maltophilia R551-3** $^{*}$ & S. maltophilia K279a** \\
\hline Number of bases & $4,648,976 \mathrm{bp}$ & $4,573,696 \mathrm{bp}$ & $4,851,126 \mathrm{bp}$ \\
$\mathrm{G}=$ C content (\%) & 67.26 & 66.3 & 66.3 \\
Number of CDSs & 4,033 & 4,039 & 4,386 \\
Coding Percentage & 88.5 & 89.4 & 88.8 \\
Average of ORF Length & $1,020 \mathrm{bp}$ & $1,013 \mathrm{bp}$ & $983 \mathrm{bp}$ \\
rRNA & 12 (genes) & 12 (genes) & 12 (genes) \\
tRNA & 72 & 73 & 74 \\
\hline
\end{tabular}

*Information presented here corresponds to the original annotation. Alterations could occur due to possible updates.

**According to the genome information provided in the corresponding NCBI gbk-data.

diagrams (Figure 4a). As presented in the figure, the number of CDSs shared between S. rhizophila and S. maltophilia R551-3 or S. maltophilia K279a is 3171 (862 specific to S. rhizophila) and 3149 (884 specific to S. rhizophila), respectively. Moreover, the orthology analysis including all three strains revealed that $762 \mathrm{CDSs}$ are unique to $S$. rhizophila DSM14405 ${ }^{\mathrm{T}}$, as these are absent from both $S$. maltophilia R551-3 and S. maltophilia K279a (Figure 4a). The percentage distribution of the $762 \mathrm{~S}$. rhizophila-unique CDSs with regard to functional gene groups revealed that genes involved in carbohydrate transport and metabolism (4.07\%), and the biogenesis and transport of cell wall, outer membrane or cytoplasmic membrane (3.02\%) are of relatively high abundance (Figure $4 b$ ).

\section{Specific gene characteristics of S. rhizophila DSM14405 ${ }^{\top}$ within the Stenotrophomonas/Xanthomonas group Quorum sensing}

Similar to various xanthomonads, S. rhizophila DSM14405 ${ }^{\mathrm{T}}$ does not possess a homoserine lactone-based quorum sensing system, but instead uses the $r p f / D S F$ system for quorum sensing and cell-cell communication. The $r p f$ (regulation of pathogenicity factors) gene cluster is responsible for the synthesis and perception of the DSF molecule which is a quorum sensing regulatory molecule of fatty acid nature with similarity to enoyl-CoA hydratase, and was first detected in Xanthomonas [22,23]. The rpfF gene product, known as DSF synthase, is essential for the synthesis of DSF $[24,25]$. Other members of the rpf gene locus (rpfC,

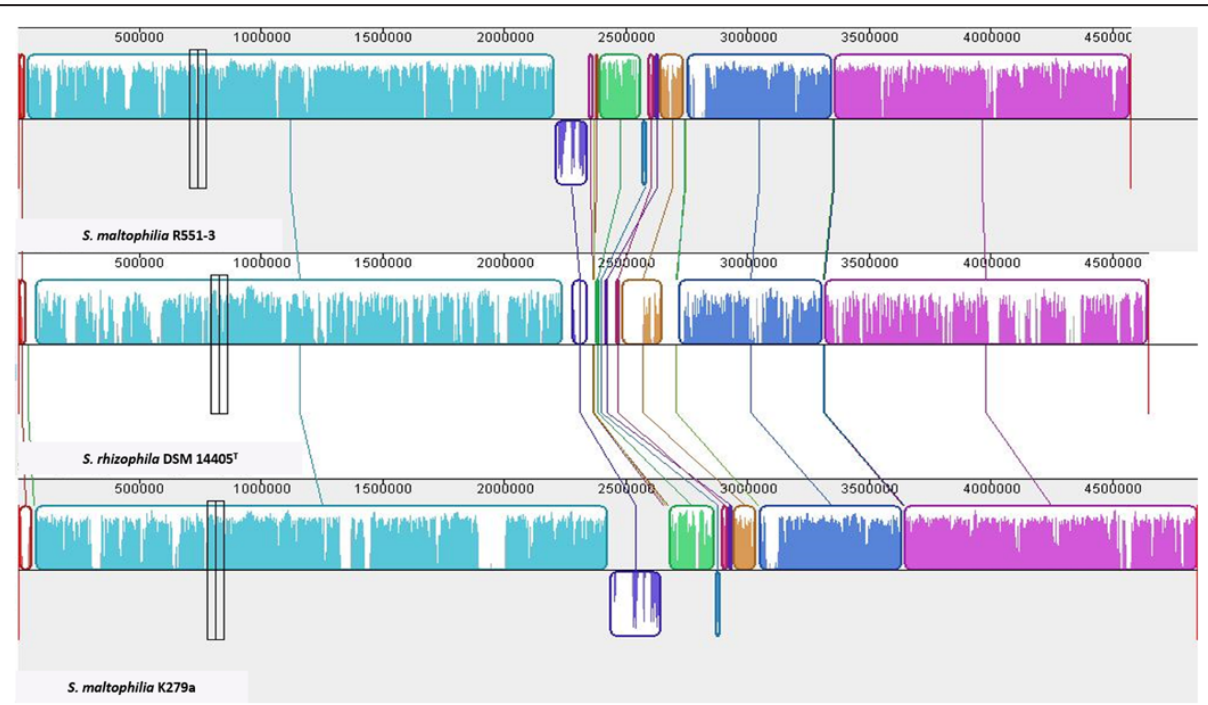

Figure 1 Genome-scale comparison for the three Stenotrophomonas strains. The plant-beneficial strains S. maltophilia R551-3 (top), S. rhizophila DSM14405 (middle), and the human pathogenic S. maltophilia K279a (bottom). The original genomic sequence of S. rhizophila DSM14405 was converted into its reverse complement to achieve the same direction for all three genomes. Homologous DNA segments among the strains are marked by boxes with the same color, while gaps correspond to non-homologous regions. There are vast regions of homology between the genome of S. rhizophila DSM14405 and both S. maltophilia R551-3 and K279a. The figure was generated using nucleotide sequences of the genomes using Mauve 2.3. 


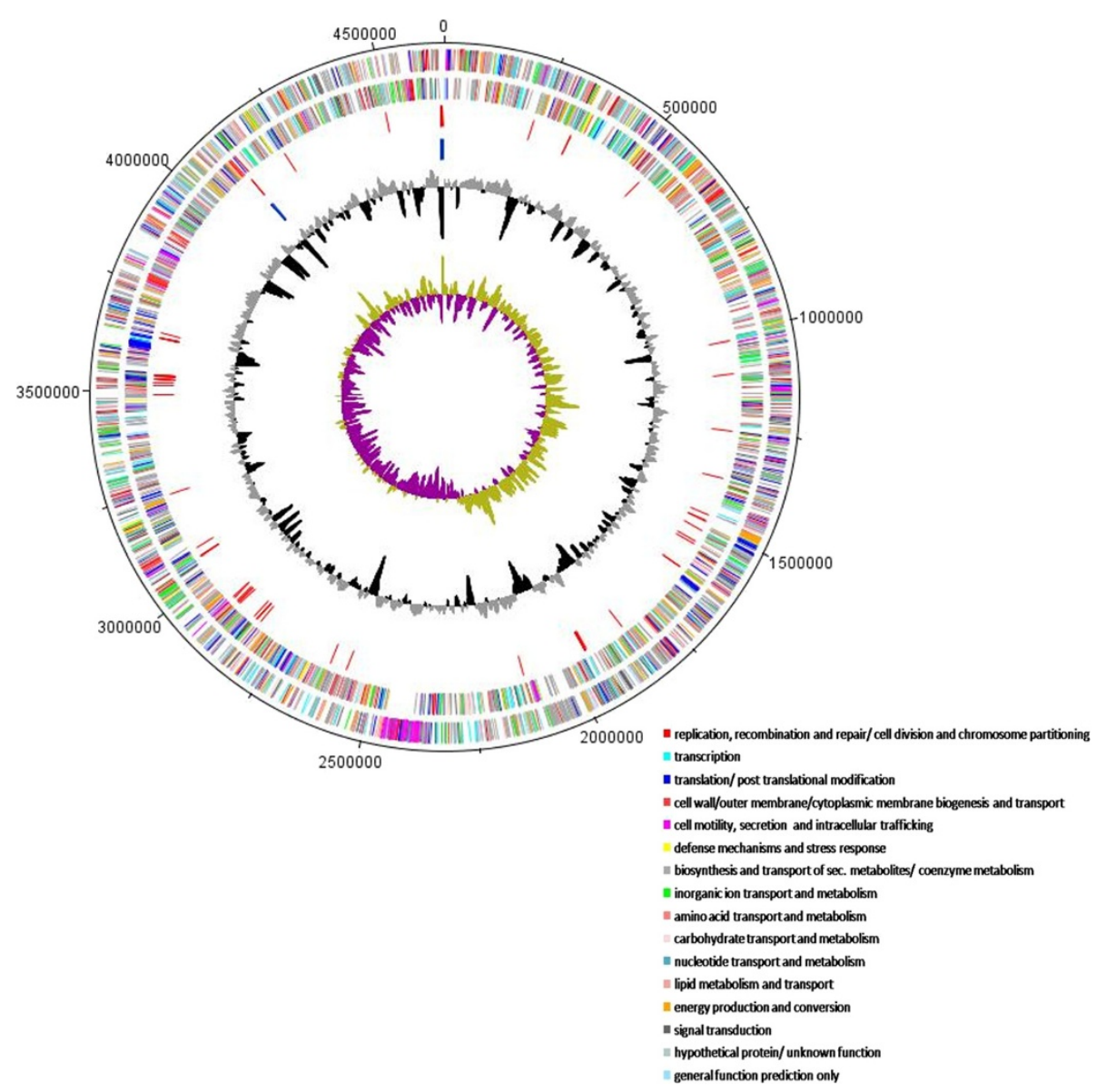

Figure 2 Circular genome map of S. rhizophila DSM14405 ${ }^{\top}$. Predicted coding sequences (CDSs) are assigned various colors with respect to cellular functions. The circles show from the outermost to the innermost: 1. DNA coordinates; 2, 3. Function-based color coded mapping of the CDSs predicted on the forward and reverse strands. Various functions are assigned different colors. 4. tRNA genes; 5. rRNA genes; 6. GC plot with regions above and below average in gray and black, respectively; 7. GC skew showing regions above and below average in dark yellow and magenta, respectively (window size: 10,000 bp). The circular genome map was constructed using DNAPlotter.

rpfG and $r p f B$ ) have been revealed to each fulfill a particular function, with the RpfC/RpfG two-component system consisting of a sensory (RpfC) and regulatory (RpfG) component that are responsible for DSF perception and signal transduction, respectively [22,26].

Similar to Stenotrophomonas strains K279a and R551-3, the core of the rpf gene locus of S. rhizophila DSM14405 ${ }^{\mathrm{T}}$ consists of four genes: $r p f B, r p f F, r p f C$ and $r p f G$. Fouhy et al. [27] described the positions of these in the humanpathogenic S. maltophilia K279a, which we found to be similar to those in the plant-associated S. maltophilia R551-3. Moreover, in both K279a and R551-3, rpfB and $r p f F$ are located on the lagging strand while $r p f C$ and $r p f G$ are located on the leading strand. In $S$. rhizophila DSM $14405^{\mathrm{T}}$, however, the $r p f B$ and $r p f F$ genes are located on the leading strand while $\operatorname{rpfC}$ and $r p f G$ are on the lagging strand. In addition, in the genome of S. rhizophila, there is a 228-nucleotide gene of unknown function on the lagging strand between $r p f F$ and $r p f B$, which extends from 2469447 to 2469674 and was annotated as Sr14405 DX03_10710. In addition, Sr14405 DX03_10710 is transcribed in the cell, as we detected the corresponding mRNA in a whole genome expression analysis approach (data not shown). There is no homologue to Sr14405 DX03_10710 in either S. maltophilia R551-3 or K279a, and its function in S. rhizophila DSM14405 ${ }^{\mathrm{T}}$ remains to be elucidated.

\section{Flagella, fimbriae}

Flagella and fimbriae-driven motility is crucial for biofilm formation and host-plant colonization by bacteria [28-30]. S. rhizophila DSM $14405^{\mathrm{T}}$ possesses several genes responsible for motility. A gene block encoding a flagellar apparatus was detected that includes 22 genes, and extends over the genome from Sr14405 DX03_10335 to DX03_10430 with most genes located on the leading strand. Another flagella-encoding gene block was also detected which includes 26 genes and is located between Sr14405 


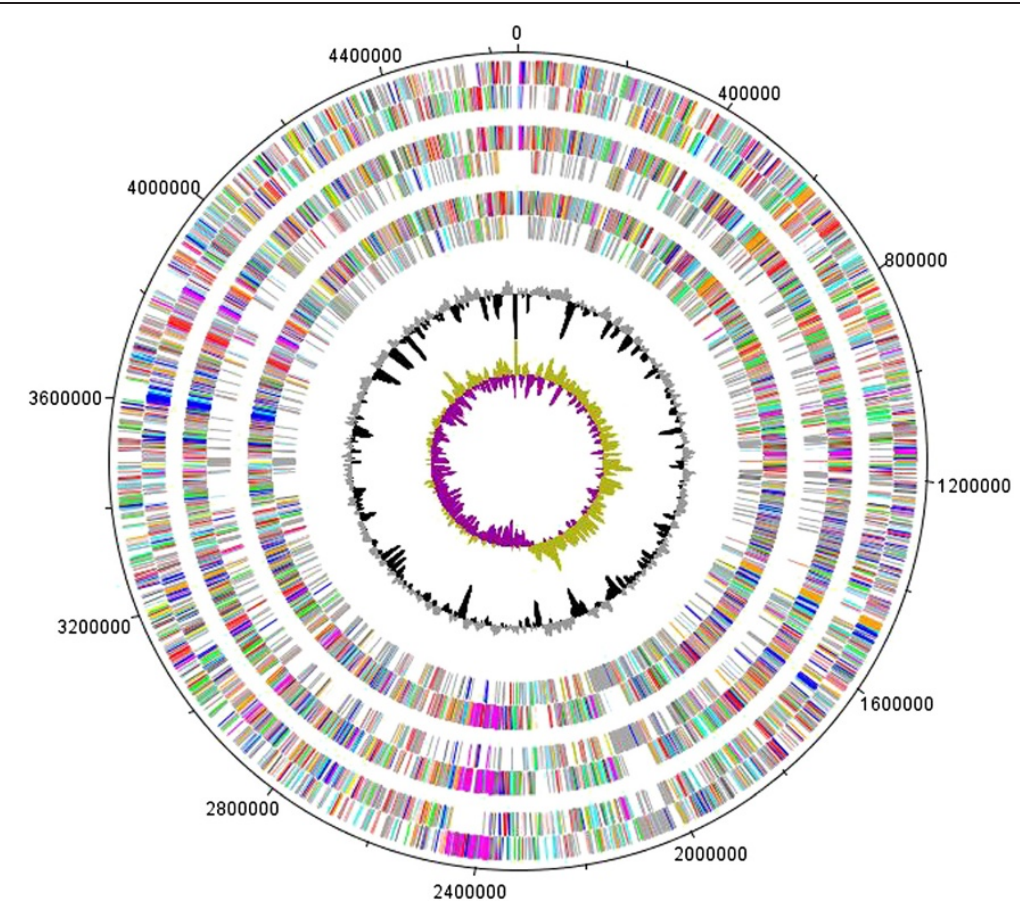

Figure 3 Gene orthology analyses between S. rhizophila DSM14405 ${ }^{\top}$, S. maltophilia R551-3 and the clinical S. maltophilia K279a. Circles show from the outermost to the innermost: 1. DNA coordinates; 2, 3. Function-based color-coded mapping of the CDSs predicted on the forward and reverse strands of the S. rhizophila DSM14405 ${ }^{\top}$ genome, respectively. 4. Orthologous CDSs shared between S. rhizophila DSM14405 ${ }^{\top}$ and S. maltophilia R551-3. 5. S. rhizophila-specific CDSs, compared with S. maltophilia R551-3. 6. Orthologous CDSs shared between S. rhizophila and S. maltophilia K279a. 7. S. rhizophila-specific CDSs, compared with S. maltophilia K279a. 8. GC plot depicting regions above and below average in gray and black, respectively; 9. GC skew showing regions above and below average in yellow green and magenta, respectively (window size: $10,000 \mathrm{bp})$. The assessment of orthologous CDSs was carried out using the reciprocal best BLASTp hit approach with an identity threshold of $30 \%$ and evalue of $10^{-6}$

DX03_10470 and DX03_10585. Furthermore, two putative fimbriae gene clusters, Sr14405 DX03_04025-DX03_04040 and Sr14405 DX03_04075-DX03_04095, were detected; other fimbriae-coding genes are scattered throughout the genome.

\section{Chitinase, extracellular proteases, antibiotic and salinity resistance}

S. rhizophila DSM $14405^{\mathrm{T}}$ is a biocontrol agent capable of synthesizing extracellular enzymes with anti-pathogenic activity such as chitinase and extracellular proteases, and is antagonistic against important fungal pathogens such as Verticillium dahliae and Rhizoctonia solani [11,31]. In addition to its direct effect, S. rhizophila DSM $14405^{\mathrm{T}}$ is thought to also indirectly promote plant growth through biological control [14]. In the genome, Sr14405 DX03_17135 codes for a putative extracellular chitinase gene, and Sr14405s DX03_03415, DX03_05635, DX03_16295, DX03_17120 are predicted to code for extracellular proteases.

In general, Stenotrophomonas species are known to show resistance against a broad range of antibiotics [8,31]. There are numerous resistance genes against various antibiotics in the genome of S. rhizophila DSM14405 ${ }^{\mathrm{T}}$, some code for general resistance, while others provide resistance against particular classes of antibiotics. The gene cluster extending from Sr14405 DX03_01540 to DX03_01550 was predicted to code for a multidrug export system. Another two multidrug resistance gene clusters were detected from Sr14405 DX03_02075 to DX03_02085 and from DX03_13460 to DX03_13470. A number of single multidrug resistance genes, such as $m d t N, m d t A$ and Sr14405 DX03_03380 are scattered throughout the genome as well. Moreover, $m a c A$ and $\operatorname{macB}$ code for the macrolide-specific efflux protein and a macrolide export ATP-binding/permease, respectively. Other identified genes include: Sr14405 DX03_06420 and ampH that code for $\beta$-lactamases, Sr14405 DX03_08150 that codes for an aminoglycoside efflux pump, and a transposon tetracycline resistance gene (tet $X)$.

S. rhizophila DSM $14405^{\mathrm{T}}$ possesses both $g g p \mathrm{~S}$ and $y c a D$, which are essential for the synthesis and transport of the important osmolyte glucosylglycerol, which provides tolerance against salinity and salt stress [32]. Both ggpS and ycaD are absent in S. maltophilia R551-3 and K279a. 


\section{S. rhizophila DSM14405}

a

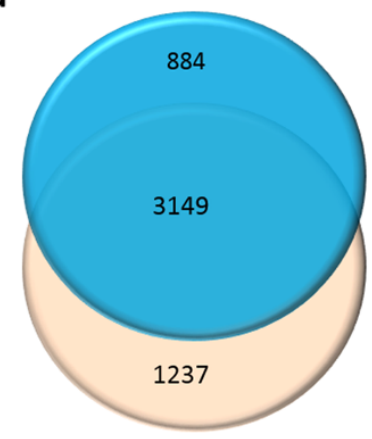

S. maltophilia K279a
S. rhizophila DSM14405

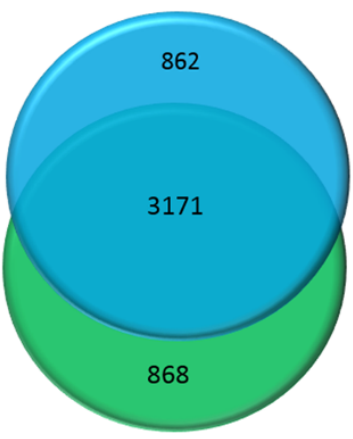

S. maltophilia R551-3 b

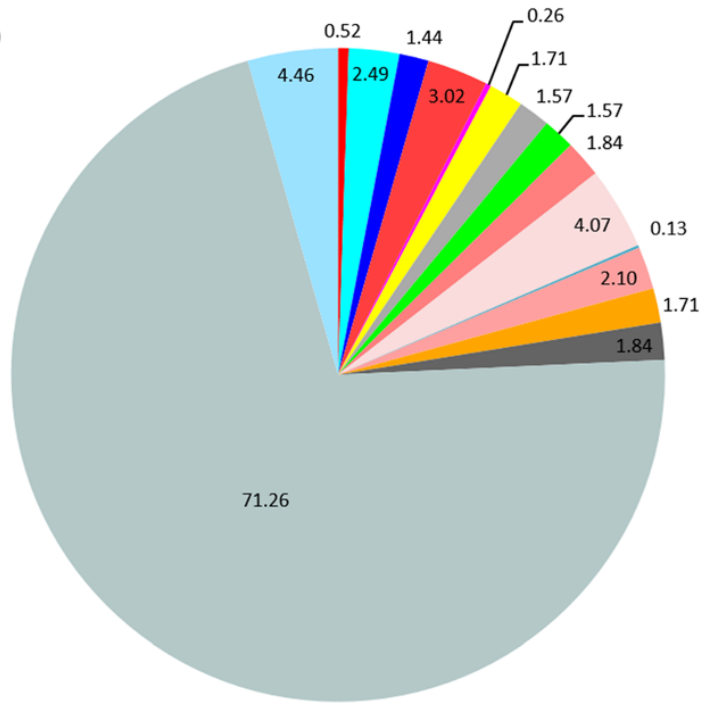

S. rhizophila DSM14405 ${ }^{\top}$

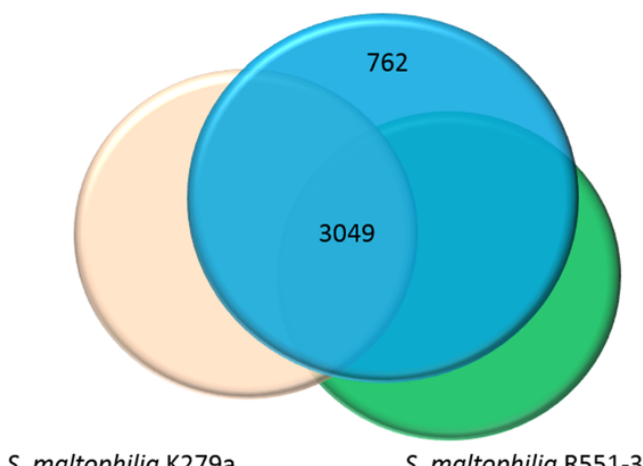

S. maltophilia K279a
S. maltophilia R551-3

- replication, recombination and repair/ cell division and chromosome partitioning
= transcription
- translation/ post translational modification
= cell wall/outer membrane/cytoplasmic membrane biogenesis and transport
= cell motility, secretion and intracellular trafficking
= defense mechanisms and stress response
= biosynthesis and transport of sec. metabolites/ coenzyme metabolism
= inorganic ion transport and metabolism
= amino acid transport and metabolism
= carbohydrate transport and metabolism
= nucleotide transport and metabolism
= lipid metabolism and transport
= energy production and conversion
m signal transduction
= hypothetical protein/ unknown function
= general function prediction only

Figure 4 Orthology analysis and the distribution of the S. rhizophila-specific CDSs with regard to cellular functions. a: Venn diagram showing the number of CDSs shared between the three strains. S. rhizophila DSM14405 ${ }^{\top}$ was used as the reference genome. 3171 and 3149 CDSs are shared between S. rhizophila and S. maltophilia R551-3 and K279a, respectively. 3049 CDSs are shared between all three strains, as a trio-analysis of the three genomes revealed. 762 CDSs are absent in both S. maltophilia R551-3 and S. maltophilia K279a, and hence unique to S. rhizophila. b: Diagram showing the percentage distribution of the $762 \mathrm{~S}$. rhizophila-specific CDSs with regard to the predicted cellular functions. Most of these are hypothetical genes (71.26\%) or CDSs of general function (4.46\%). Other S. rhizophila-unique genes showing a relative abundance are involved in carbohydrate transport and metabolism (4.07\%), and cell wall, outer membrane, and cytoplasmic membrane biogenesis (3.02\%).

\section{Surface polysaccharides}

Homologs to $x a n \mathrm{~A}, x a n B$, and $r m l A C$ were detected in S. rhizophila DSM14405 ${ }^{\mathrm{T}}$. These genes are involved in the biosynthesis of the Xanthomonas well-known surface polysaccharide xanthan, in biofilm formation [33] and the biosynthesis of lipopolysaccharides. It is noteworthy that S. rhizophila DSM14405 ${ }^{\mathrm{T}}$, similar to other members of the Stenotrophomonas species known so far, does not have a gum gene cluster and therefore cannot produce xanthan.

The bacterial capsule is an extracellular structure usually composed of polysaccharides which is considered an important virulence factor in surface adherence, antibiotic resistance, and preventing phagocytosis $[34,35]$. Reckseidler et al. [36] demonstrated that the ability to synthesize capsule is crucial for virulence in the human pathogenic Burkholderia. In S. rhizophila DSM14405 ${ }^{\mathrm{T}}$, a gene block from Sr14405 DX03_11185 to DX03_11265 is homologous to a capsule biosynthesis gene cluster of Pseudomonas pseudomallei, described by [37]. This gene block includes genes that code for proteins of various functions such as signal transduction, transport, and biosynthesis of capsule polysaccharide components. None of the genes present in the S. rhizophila capsule gene block were detected in S. maltophilia R551-3 and K279a. 
Alginate, an exopolysaccharide, is involved in the development and architecture of biofilms and protects bacteria from antibiotics and other antibacterial mechanisms [38-40]. Alginate biosynthesis genes algI and algJ code for the poly (beta-D-mannuronate) O-acetylase and the alginate biosynthesis protein, respectively. While both were detected in S. rhizophila DSM14405 ${ }^{\mathrm{T}}$, neither the plant-associated strain S. maltophilia R5513 nor the human pathogenic S. maltophilia K279a contained either of these genes. algI is preceded by four genes which are also absent from both S. maltophilia R551-3 and K279a, with one of these being homologous to a gene coding for a cell morphology protein from the biocontrol agent $P$. fluorescens SBW25.

\section{Secretion systems}

While type II and V secretion system genes were identified in S. rhizophila DSM $14405^{\mathrm{T}}$, there is no type III secretion system present, as this is typical of Stenotrophomonas. Although there are several genes belonging to the type IV secretion system, a complete gene set was not detected in $S$. rhizophila DSM14405 ${ }^{\mathrm{T}}$. Furthermore, a gene block extending from Sr14405 DX03_08870 to DX03_09120 was identified in S. rhizophila, which includes numerous genes of the type VI secretion system (T6SS) including icmF, $\operatorname{imp} A$, genes belonging to the Hcp1 family, and genes coding for proteins with a T6SS Rhs element. With the exception of Sr14405 DX03_09050, DX03_09095, and DX03_09115, there were no homologs in S. maltophilia K279a and R551-3 to any of the genes of the S. rhizophila type VI secretion system block.

One genus, two entirely different habitats and life styles? : Genome comparison between S. rhizophila DSM14405 ${ }^{\top}$ and S. maltophilia K279a

All genes of the plant growth-promoting environmental S. rhizophila DSM $14405^{\mathrm{T}}$ and the clinical human pathogenic S. maltophilia K279a were compared. While absent from S. maltophilia K279a, numerous S. rhizophila-specific genes play a role in host-plant colonization. Some of these genes, as described earlier, are crucial for surface attachment, biofilm formation, secretion systemsdriven molecular mechanisms, and tolerance of environmental stress such as high soil salinity. In addition, another S. rhizophila-specific gene was predicted to code for spermidine synthase (speE). Spermidine is a plant growth regulator and has been recently shown to strongly promote the growth of arugula plants [41]. There are also S. rhizophila-specific genes that are predicted to be involved in the biodegradation of bacterial and plant cell wall. $\mathrm{m} l t D$, located closely to the $S$. rhizophila type VI secretion system gene block, codes for muramidase that plays an important role in the bacterial cell wall breakdown. Furthermore, a gene block stretching from Sr14405
DX03_09870 to DX03_09895 was predicted to code for several genes involved in the breakdown of plant cell walls.

As a next step, the $S$. rhizophila DSM $14405^{\mathrm{T}}$ having a counterpart in the plant-associated S. maltophilia R5513 , but with no homologous genes in the clinical $S$. maltophilia K279a were studied. Of these 88 genes, several help with the need to adapt to the plant and rhizosphere as the natural habitat. For instance, the endo-1,4-betaxylanase $\mathrm{B}$ gene $(x y n B)$ is involved in plant cell wall biodegradation. Other genes conserved in $S$. rhizophila DSM $14405^{\mathrm{T}}$ and S. maltophilia R551-3 are the ferrichrome receptor genes, $f c u A$ and $f h u A$ which code for siderophore receptors, and the outer membrane adhesin-like gene (Sr14405 DX03_14745). Table 2 presents a list of selected $S$. rhizophila DSM $14405^{\mathrm{T}}$-specific genes with no homologs in the human pathogenic $S$. maltophilia $\mathrm{K} 279 \mathrm{a}$, together with their biological role. The complete list of the $884 \mathrm{~S}$. rhizophila DSM14405 ${ }^{\mathrm{T}}$ specific genes which are not present in S. maltophilia K279a is provided in Additional file 2: Table S1.

Next, the genomes of S. rhizophila DSM $14405^{\mathrm{T}}$ and $S$. maltophilia K279a were compared using the latter as the reference, which revealed that 1230 genes are specific to the human pathogenic K279a with no homologs in the plant-growth promoting $S$. rhizophila. While many of these genes are hypothetical or have unknown protein function, others play a specific role. Of the genes with a known or predicted function, many are involved in pathogenicity and virulence. For example, the gene block extending from Smlt 2997 to 3005 codes for proteins of the type IV secretion system, which is known to have a dual role of both horizontal gene transfer and pathogenicity. Other S. maltophilia K279a-specific virulence genes are Smlt 3048, 3683, and 4452, which were predicted to code for an outer membrane-located adhesin, hemolysin, and hemagluttinin, respectively. Furthermore, Smlt 4391, and $a f a D$ code for putative exopolysaccharide and adhesin, respectively. In addition, a K279a-specific putative fimbriae gene block (Smlt 706-709) codes for fimbrial adhesin proteins and their chaperones. Moreover, there are also several S. maltophilia K279a heat shock and chaperone-encoding genes that have no homologs in $S$. rhizophila DSM14405 ${ }^{\mathrm{T}}$, such as Smlt 1818 and Smlt 4629-4631, as both code for heat shock chaperone proteins. Synthesis of chaperones to cope with temperaturecaused stress is fundamental for the natural habitat of $S$. maltophilia K279a as a human pathogenic strain. There are various S. maltophilia K279a-specific genes coding for antibiotic resistance and multidrug efflux pumps that are absent from S. rhizophila DSM $14405^{\mathrm{T}}$. For instance, smeABC (Smlt 4474-4476), which code for a multidrug efflux pump typical of $S$. maltophilia strains, is not present in DSM14405 ${ }^{\mathrm{T}}$. Nevertheless in total, six of the nine 
Table 2 Selected S. rhizophila DSM14405 ${ }^{\top}$-specific genes revealing no homologs in the human pathogenic S. maltophilia K279a with their role in coping with the environment and bacteria-plant interactions

\begin{tabular}{|c|c|c|}
\hline Bilogical role & Gene/Locus tag & (Putative) Product \\
\hline Plant growth promotion & DX03_01135(speE) & Spermidine synthase \\
\hline \multirow{6}{*}{ Secretion System } & DX03_08905 & lipoprotein \\
\hline & DX03_08920 & type VI secretion system effector \\
\hline & DX03_08950 & Rhs element Vgr protein with a type VI secretion system protein domain \\
\hline & DX03_09065 (icmf) & type VI section system protein \\
\hline & DX03_09080 & type VI section system-associated protein ImpA family \\
\hline & DX03_09090 & Rhs element Vgr protein with a type VI secretion system protein domain \\
\hline \multirow{6}{*}{ Bacterial and Plant cell wall breakdown } & DX03_06125 (m/tD) & Muramidase \\
\hline & DX03_09870 (xsa) & xylosidase/arabinosidase \\
\hline & DX03_09875 (cbg1) & beta-glucosidase \\
\hline & DX03_09880 & sialate O-Acetylesterase \\
\hline & DX03_11570 (aguA) & alpha-glucuroidase \\
\hline & DX03_20070 (xynB) & endo-1,4-beta-xylanase B \\
\hline \multirow{9}{*}{ Resistance towards antibiotics and salinity } & DX03_01540_42 (mdtABC) & $\begin{array}{l}\text { three multidrug resistance proteins; form together a } \\
\text { multidrug resistance protein channel }\end{array}$ \\
\hline & DX03_06420 & beta-lactamase \\
\hline & DX03_06600 (tetX) & transposon tetracycline resistance protein \\
\hline & DX03_06745 (ampH) & beta-lactamase \\
\hline & DX03_08150 & aminoglycoside efflux protein \\
\hline & DX03_19375,mdtA,mdtN & multidrug resitance proteins \\
\hline & DX03_19380 & transposon tetracycline repressor protein \\
\hline & DX03_04600 (ggpS) & $\begin{array}{l}\text { glucoslglycerol-phosphate synthase; essential for the } \\
\text { synthesis of the osmolyte glucoslglycerol }\end{array}$ \\
\hline & DX03_04605 (ycaD) & glucoslglycerol transporter \\
\hline \multirow{7}{*}{ Surface attachment and biofilm formation } & DX03_11195 (yccZ) & capsule polysaccharide export protein \\
\hline & DX03_11200 (ymcC) & Lipoprotein \\
\hline & DX03_11240 & capsule polysaccharide biosynthesis protein \\
\hline & DX03_11265 (wcaJ) & colanic biosynthesis UDP-glucose lipid transferase \\
\hline & DX03_14745 & adhesin-like protein \\
\hline & DX03_17015 (algl) & poly (beta-D-mannuronate) O-acetylase \\
\hline & DX03_17020 (algl) & alginate bioynthesis protein Algl \\
\hline Iron uptake & fсuA, fhuA & ferrichrome receptor proteins \\
\hline
\end{tabular}

K279a genes that code for multidrug efflux pumps involved in antibiotic resistance [20] have a homolog in $S$. rhizophila DSM14405 ${ }^{\mathrm{T}}$. Other S. maltophilia K279aspecific genes with respect to antibiotic resistance include $\boldsymbol{\beta}$-lactamase genes, Smlt 4159 and 4211, and Smlt 1071 $(q n r B)$, which codes for a fluoroquinolone resistance protein. Moreover, several heavy metal resistance genes for the transport of arsenate, mercuric, and copper are another genomic characteristic of the human pathogenic $S$. maltophilia K279a. Table 3 shows various S. maltophilia K279a genes with no homologs in the plant growthpromoting S. rhizophila DSM $14405^{\mathrm{T}}$ together with their products and biological roles. The complete list of the
1230 S. maltophilia K279a-specific genes is presented in additional file 3: Table S2. Figure 5 represents a model that summarizes crucial specific mechanisms harnessed by $S$. rhizophila DSM14405 ${ }^{\mathrm{T}}$ and S. maltophilia K279a to best adapt to their particular habitats together with the corresponding genes, and the important mechanisms that are shared between both species.

The temperature limit: the transcriptional response of S. rhizophila DSM $14405^{\top}$ to $35^{\circ} \mathrm{C}$

In contrast to other Stenotrophomonas strains including S. maltophilia K279a and R551-3, S. rhizophila DSM14405 ${ }^{\mathrm{T}}$ is not able to grow at $37^{\circ} \mathrm{C}$, which is a critical temperature 
Table 3 Selected human pathogenic S. maltophilia K279a-specific genes, which are involved in virulence and pathogenicity, and reveal no homologs in S. rhizophila DSM $14405^{\top}$

\begin{tabular}{|c|c|c|}
\hline Bilogical role & Gene/Locus tag & (Putative) Product \\
\hline \multirow{8}{*}{ Virulence } & smf-1,0709 & fimbrial adhesin proteins \\
\hline & 0707 & pili chaperone protein \\
\hline & mrkC & outer membrane usher protein \\
\hline & 3048 & Hep Hag family adhesin \\
\hline & wbpV (3683) & hemolysin protein \\
\hline & 4391 & exopolysaccharide synthesis protein \\
\hline & $\mathrm{afaD}$ & Non-fembrial adhesin \\
\hline & 4452 & cell surface haemagluttinin protein \\
\hline \multirow{3}{*}{ Secretion system-mediated pathogenicity, horizontal gene transfer } & 2997,3000 & type IV secretion system transmembrane proteinS \\
\hline & $2999,3002,3003$ & type IV secretion conjugal transfer proteins \\
\hline & 3005 & VirB9 protein \\
\hline \multirow{3}{*}{ Heat shock resistance, chaperones } & 1818 & heat shock chaperone protein \\
\hline & hscC & chaperone heat shock Hsp70 protein \\
\hline & 4630,4631 & heat shock chaperone protein \\
\hline \multirow{6}{*}{ Antibiotic resistance } & qnrB & flouroquinolone resistance protein \\
\hline & 2642 & macrolide-specific ABC-type efflux \\
\hline & 4159,4211 & beta-lactamase \\
\hline & smeC (oprM) & multidrug efflux system outer membrane protein \\
\hline & smerB & multidrug efflux protein \\
\hline & smeA (acrA) & drug resistance efflux protein \\
\hline
\end{tabular}

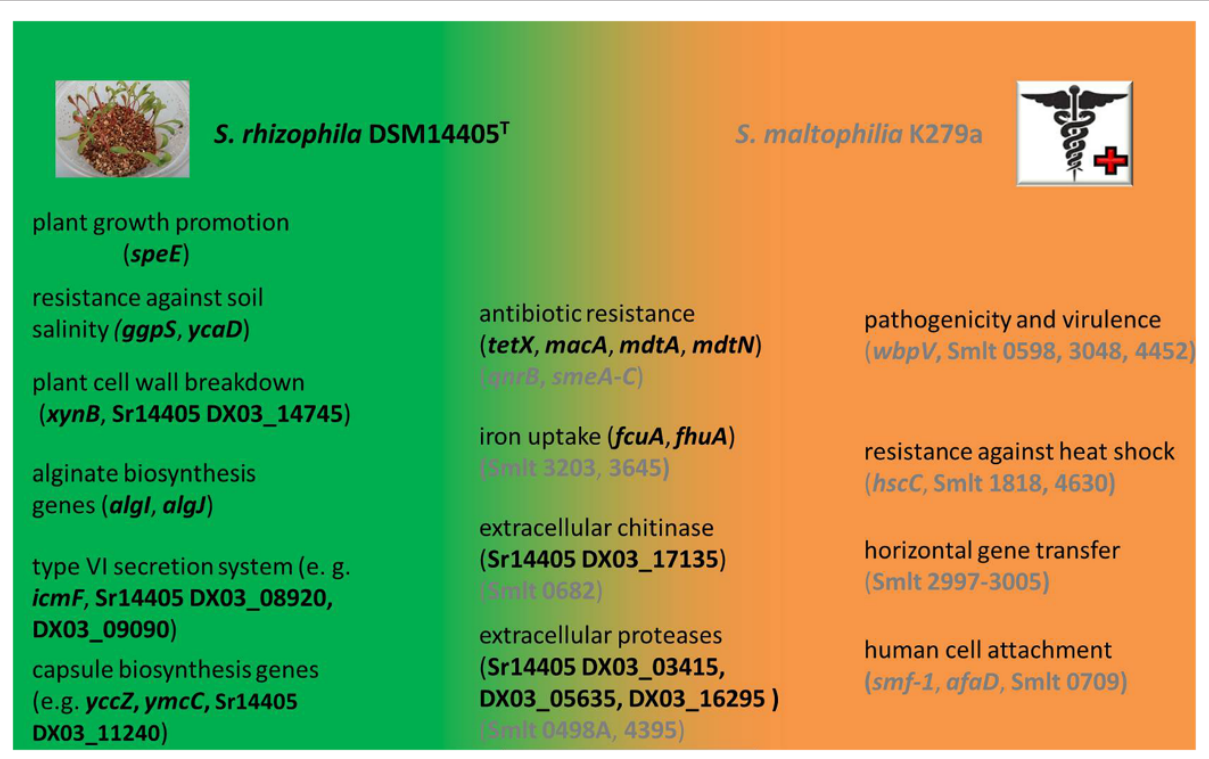

Figure 5 Model showing the specific and shared mechanisms used by S. rhizophila and S. maltophilia K279a. The plant growth promoting and biocontrol agent S. rhizophila DSM14405 ${ }^{\top}$ and the human-pathogenic clinical S. maltophilia K279a each use particular mechanisms that rely on species-specific genes to best adapt and perform in their habitats. The S. rhizophila-specific genes are shown in black while those genes in gray are specific to S. maltophilia K279a. Nevertheless, other crucial mechanisms such as ensuring access to biologically available iron and resistance against antibiotics are shared between both species (middle). 


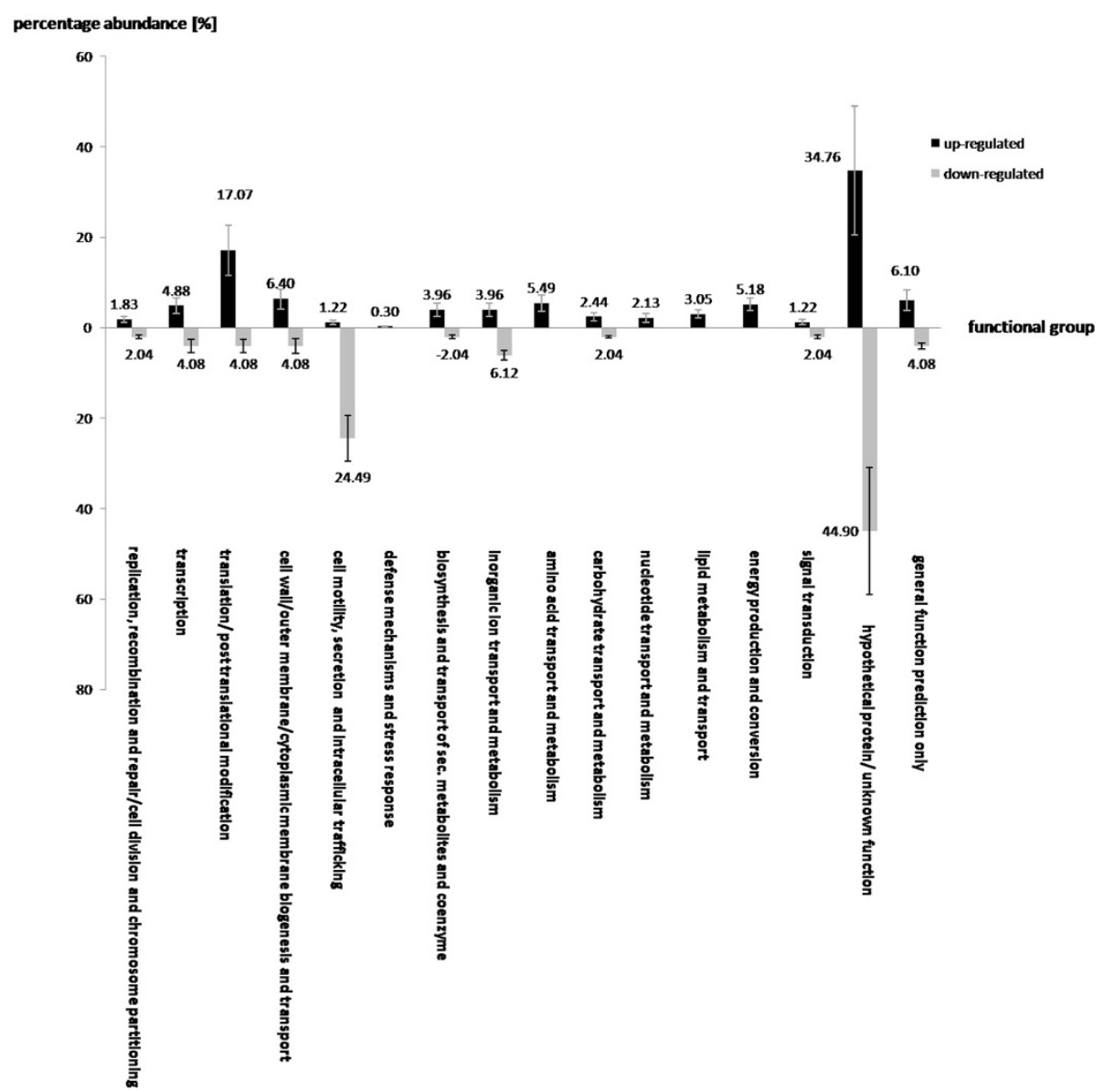

Figure 6 The impact of heat shock $\left(35^{\circ} \mathrm{C}\right)$ on the gene expression of S. rhizophila DSM14405 ${ }^{\top}$. Genes responsible for translation and post-translational modification, the metabolism and transport of amino acids, nucleotides, lipids, and the production and conversion of energy are up-regulated while genes involved in cell motility and intracellular trafficking are strongly down-regulated. The values above each column correspond to the percentage abundance of the corresponding functional gene group relative to the total count of the up and down-regulated genes. The transcription fold change for each CDS corresponds to the ratio calculated for S. rhizophila treated with $35^{\circ} \mathrm{C}$ compared to $30^{\circ} \mathrm{C}$. Data are presented as the mean value of two independent replicates. The error bar shown on each functional group corresponds to the mean value of errors for all genes belonging to that functional group.

for strains to colonize the human body. To understand why this strain and other S. rhizophila strains cannot grow at this temperature and to reveal the underlying molecular mechanisms behind, the impact of high temperature $\left(35^{\circ} \mathrm{C}\right)$ on S. rhizophila DSM $14405^{\mathrm{T}}$ was studied using a transcriptomic approach. In comparison with growth at $30^{\circ} \mathrm{C}, 328$ and 49 genes are significantly up and downregulated, respectively, as the result of a severe heat shock of $35^{\circ} \mathrm{C}$ (Figure 6). As presented, genes responsible for translation and post-translational modification along with other functional gene groups including those involved in the metabolism and transport of amino acids, nucleotides, lipids, and the production and conversion of energy are up-regulated at $35^{\circ} \mathrm{C}$. Moreover, those genes whose functions are only generally known are also mostly up-regulated suggesting that, in S. rhizophila DSM14405 ${ }^{\mathrm{T}}$, a significant number of the genes involved in the response to severe heat shock code for proteins with unknown function. In contrast, genes responsible for cell motility, secretion and intracellular trafficking show a pronounced down-regulation at $35^{\circ} \mathrm{C}$, making up $24.49 \%$ of all down-regulated genes. Of the genes with a significant transcription fold change as the result of the shift from 30 to $35^{\circ} \mathrm{C}$, some code for products with known biological function (Table 4). As shown in the table, genes coding for chaperones involved in both general stress and heat shock specific response including $d n a J-K$, and groS-L and $h t p G$, respectively, are up-regulated at $35^{\circ} \mathrm{C}$. Other up-regulated genes include rpoH which codes for the heat shock specific sigma factor, and numerous genes coding for proteases that are responsible for the degradation of stress-denatured proteins. Furthermore, genes responsible for cell suicide mechanisms, Sr14405 DX03_18795 and DX03_18990, are also 
Table 4 Selected S. rhizophila DSM $14405^{\top}$ genes with known biological roles impacted by the $35^{\circ} \mathrm{C}$ heat shock

\begin{tabular}{|c|c|c|c|}
\hline Gene/Locus tag & (Putative) Product & $\begin{array}{l}\text { Transcription } \\
\text { fold change }\end{array}$ & Biological role \\
\hline DX03_01700 (rpoH) & sigma 32 & 3.0 & heat shock sigma factor \\
\hline DX03_05495 & negative regulator of sigma 24 & 3.1 & transcription regulation \\
\hline DX03_11865 (dna) & chaperone DnaJ & 3.1 & stress response \\
\hline DX03_11870 (dnaK) & chaperone DnaK & 2.9 & stress response \\
\hline DX03_11875 (grpE) & chaperone complex protein & 2.6 & prevents the aggregation of stress-denatured proteins \\
\hline DX03_02015 (groS) & co-chaperonin GroES & 2.4 & heat shock chaperone \\
\hline DX03_02020 (grol) & chaperonin GroEL & 1.9 & heat shock chaperone \\
\hline DX03_12190 (htpG) & heat shock chaperone & 2.0 & heat shock response \\
\hline DX03_07545 (fkpA) & chaperone & 2.0 & stress response \\
\hline DX03_10250 (clpA) & ATPase with chaperone activity & 1.8 & stress response \\
\hline DX03_14890 (yraA) & protease & 2.3 & degradation of abnormal/stress-denatured proteins \\
\hline DX03_05505 (degP) & protease & 2.1 & degradation of abnormal/stress-denatured proteins \\
\hline DX03_02875 (hs/V) & protease & 1.5 & degradation of abnormal/stress-denatured proteins \\
\hline DX03_06825 (htpX) & protease & 1.5 & $\begin{array}{l}\text { degradation of abnormal/stress-denatured } \\
\text { proteins due to heat shock }\end{array}$ \\
\hline DX03_15635 (lon) & Lon Protease & 1.5 & degradation of abnormal/stress-denatured proteins \\
\hline DX03_03030 (prc) & protease & 1.5 & Protein degradation under thermal stress \\
\hline DX03_05315 (cbpA) & $\begin{array}{l}\text { DNA-binding protein; accessory } \\
\text { protein for DnaJ }\end{array}$ & 1.8 & heat shock response \\
\hline DX03_11520 (gtaB) & UTP-glucose-1-phosphate uridylyltransferase & 1.6 & general stress protein \\
\hline DX03_18990 & killer protein & 2.4 & suicide mechanism \\
\hline DX03_18795 & entericidin $E c n A B$ & 3.3 & suicide mechanism \\
\hline DX03_06640 & sigma 24 & 0.3 & primary general stress sigma factor \\
\hline DX03_04075 & fimbrial assembly family protein & 0.6 & pili-driven motility \\
\hline DX03_04080 & pilus assembly protein $\mathrm{PilO}$ & 0.6 & pili-driven motility \\
\hline DX03_04085 & pilus assembly protein PilP & 0.6 & pili-driven motility \\
\hline DX03_04090 (pilQ) & pilus assembly protein PilQ & 0.6 & pili-driven motility \\
\hline DX03_04405 (fimA) & fimbrial protein & 0.6 & pili-driven motility \\
\hline DX03_04895 (pil) & fimbrial protein & 0.6 & pili-driven motility \\
\hline DX03_10405 (flic) & A-type flagellin & 0.5 & pili-driven motility \\
\hline DX03_12885 (ppdD) & fimbrial protein pilin & 0.4 & pili-driven motility \\
\hline DX03_12890 & type 4 fimbrial biogenesis & 0.6 & pili-driven motility \\
\hline DX03_12905 & pre-pilin leader sequence & 0.5 & pili-driven motility \\
\hline DX03_12910 & pre-pilin leader-like sequence & 0.5 & pili-driven motility \\
\hline
\end{tabular}

Fold changes correspond to the S. rhizophila DSM $14405^{\top}$ treated with $35^{\circ} \mathrm{C}$ compared to $30^{\circ} \mathrm{C}$ (control).

up-regulated as the result of the shift from 30 to $35^{\circ} \mathrm{C}$. In contrast, as shown in Table 4 genes coding for pili-driven cell motility are negatively affected at $35^{\circ} \mathrm{C}$.

\section{Discussion}

In the present work, we characterized the genomic features of the plant growth promoting and biocontrol agent S. rhizophila DSM14405 ${ }^{\mathrm{T}}$. In addition, the comparison between the genome of S. rhizophila with other environmental and clinical Stenotrophomonas model strains, S. maltophilia R551-3 and K279a, respectively revealed a great deal of homology shared among all three bacteria. Surprisingly, the comparison of S. rhizophila's genes with either of the other two strains showed that the total number of genes shared between S. rhizophila and the human-pathogenic S. maltophilia K279a is only slightly less than the total gene number shared with the plant-associated beneficial S. maltophilia R551-3 strain. Given this significant degree of similarity, we concluded that the immense difference between $S$. 
rhizophila and S. maltophilia K279a with regard to the habitat and lifestyle must be based upon the role of those genes that are specific to either of the strains and absent from the other. On this account, a number of $S$. rhizophila specific genes coding for products of known function were detected and classified according to their biological roles. These include genes involved in plant growth promotion, plant cell wall degradation, biofilm formation, resistance against salinity and the type VI secretion system (T6SS).

Clearly as an environmental plant-associated strain, $S$. rhizophila faces particular habitat-specific factors such as those that impose some sort of osmotic stress on the cell including root exudates and salinity. In a study published recently, we used a transcriptomic approach to study the manner of response of S. rhizophila DSM14405 to osmotic stress [42]. Surprisingly, the combination of both the genomic and transcriptomic data reveals that a significant number of the genes with known biological role that are greatly involved in osmotic stress protection including $\operatorname{cbg} 1, x y n B, \operatorname{ggp} S, y c a D$, algJ and the T6SS are specific to S. rhizophila and absent from S. maltophilia K279a. This finding confirms the importance of the strain specific genes in the adaptation and performance of $S$. rhizophila in its natural habitat. As a clinical humanpathogenic strain, S. maltophilia K279a also possesses particular genetic potentials that make possible its lifestyle (Table 3, Figure 5). The role of type IV secretion system, hemolysin and other adherence components in virulence and pathogenicity was described earlier. A yet more crucial feature of S. maltophilia K279a with regard to performance in its habitat, however, is perhaps its ability to grow at $37^{\circ} \mathrm{C}$. Also in this regard, this strain possesses specific heat shock resistance genes that are absent from $S$. rhizophila.

As mentioned earlier, S. rhizophila DSM $14405^{\mathrm{T}}$ is not able to grow at $37^{\circ} \mathrm{C}$. To understand the manner of response of $S$. rhizophila to severe growth-inhibiting temperature, a genome-wide gene expression analysis was performed at $35^{\circ} \mathrm{C}$ using transcriptomics. The positive impact of the growth temperature at $35^{\circ} \mathrm{C}$ compared to $30^{\circ} \mathrm{C}$ on several functional gene groups including those responsible for the metabolism and transport of amino acids, lipids and the energy providing genes is due to the heat stress that the cell is coping with. Furthermore, studying the expression of single genes revealed that those genes coding for general and heat shock specific chaperones, various proteases that break down stress-denatured, abnormal proteins are upregulated. For example at $35^{\circ} \mathrm{C}$, the primary general stress sigma factor 24 coding gene, which is strongly expressed at an earlier stage under cell stress, and initiates the expression of $r p o H$ (the heat shock specific sigma factor 32), specific chaperones (e. g. $f k p A$ ) and protease coding genes (e. g. $\operatorname{deg} P$ ) is down-regulated while $\mathrm{rpoH}$, and other response mechanisms show upregulation. This confirms an advanced state of shock for S. rhizophila at $35^{\circ} \mathrm{C}$, at which heat shock specific response mechanisms are strongly activated. In this regard, the up-regulation of Sr14405 DX03_18795 and DX03_18990 (absent from S. maltophilia K279a) which code for toxin/antidote-based suicide systems further illustrate the mechanisms used by S. rhizophila DSM14405 ${ }^{\mathrm{T}}$ to respond to the severe heat stress. Moreover, reduced cell motility, which is also part of these response mechanisms, is presumably due to the fact that costly processes such as motility are to be minimized during harsh stress times.

\section{Conclusions}

Overall, there is a great deal of similarity between the beneficial and human-pathogenic Stenotrophomonas model strains. Nevertheless, the adaptation to the habitat and lifestyle to guarantee the survival of the species is cared for by mechanisms specific to either of the groups, and many genes underlying these mechanisms in S. rhizophila DSM $14405^{\mathrm{T}}$ are strain-specific. Furthermore according to the genomic and transcriptomic analyses together with its physiological characteristics, $S$. rhizophila poses no threat to human health and could hence be safely applied in biotechnology.

\section{Methods}

Bacterial strain

S. rhizophila DSM14405 ${ }^{\mathrm{T}}$ (syn. e-p10 and p69) was isolated from the rhizosphere of oilseed rape in Rostock, Germany [11,31].

\section{Genome sequencing, assembly, annotation of $S$ rhizophila DSM14405 ${ }^{\top}$}

The genome of $S$. rhizophila DSM14405 ${ }^{\mathrm{T}}$ was sequenced using a combination of next generation sequencing platforms. A first draft assembly based on 905,689 reads of an $8 \mathrm{kbp}$ paired-end library (Roche 454 GS, FLX Titanium, Helmholtz Center Munich, Germany) with a total of 167.1 Mbps (36-fold coverage) was generated with Newbler 2.6 (Roche Diagnostics, Penzberg, Germany). This assembly consisted of 175 contigs, 122 of which could be joined into a single circular scaffold. Gaps resulting from repetitive sequences were resolved by in silico gap filling, remaining gaps were closed by PCR followed by Sanger sequencing or by long reads from a Pacific BioSciences sequencing run (PacBio RS, 150,305 reads, 174.8 Mbps, 38-fold coverage, GATC, Konstanz, Germany), yielding a draft genome of 4,648,936 bps. To improve the quality of the sequence by eliminating 454 sequencing artefacts in homopolymer stretches, the 
genome was subsequently sequenced using the Illumina paired-end method (Illumina HiSeq 2000, 15,086,654 reads, $1508 \mathrm{Mbp}$; 324-fold coverage, Ambry Genetics, Aliso Viejo, CA, USA). The Illumina reads were aligned to the draft genome with CLC Genomics Workbench 4.7.2 (CLC bio, Aarhus, Denmark). The final consensus sequence was derived by counting instances of each nucleotide at a position and then letting the majority decide the nucleotide in the consensus sequence. Genes were identified with the Prodigal gene finder [43], ARAGORN [44], and RNAmmer 1.2 [45]. Functional annotation of the predicted genes was performed using BASys [46], which provides annotations with respect to Clusters of Orthologous Groups (COG) [47], Pfam [48] and Gene Ontology (GO) [49]. The final genome includes 4,648,976 bases with a GC content of $67.26 \%$.

\section{Comparative genomics and bioinformatic analyses}

Whole genome comparisons between S. rhizophila DSM14405 ${ }^{\mathrm{T}}$, S. maltophilia R551-3 and K279a were performed using Mauve 2.3 [50] and Artemis Comparison Tool (ACT) [51]. In the approach using Mauve, the Progressive Mauve algorithm was used to score the genome alignment. DNAPlotter [52] was used for circular genome visualization. Orthologous coding DNA sequences (CDS) shared between S. rhizophila DSM14405 ${ }^{\mathrm{T}}$ and the other two Stenotrophomonas were assessed by performing reciprocal BLASTp best hits with an identity and e-value threshold of $30 \%$ and $10^{-6}$, respectively.

Cell culture growth conditions for transcriptomic analyses S. rhizophila DSM $14405^{\mathrm{T}}$ was grown in $100 \mathrm{ml}$ Erlenmeyer flasks containing $50 \mathrm{ml} \mathrm{CAA} \mathrm{minimal} \mathrm{medium} \mathrm{at} 30^{\circ} \mathrm{C}$ under agitation until $\mathrm{OD}_{600}$ of 0.9 was reached. To introduce heat shock prior to RNA extraction, some of the flasks containing the culture were exposed to $35^{\circ} \mathrm{C}$ for $2 \mathrm{~h}$ under identical agitation conditions while the rest of the flasks remained at $30^{\circ} \mathrm{C}$ for the same period of time (control).

\section{RNA extraction and transcriptomic analyses}

RNA was extracted from $250 \mu \mathrm{l}$ of each of the cultures exposed to $30^{\circ} \mathrm{C}$ and $35^{\circ} \mathrm{C}$ in duplicates using the RNeasy Mini Kit and the RNAprotect ${ }^{\oplus}$ Bacteria Reagent according to the manufacturer's protocol (Qiagen, Hilden, Germany). Total RNA was sent to a sequencing service offered by GATC Biotech (Konstanz, Germany) where the samples were processed according to company's proprietary protocols including depletion of rRNA (Ribo-Zero RNA Removal Kit, Epicentre, Madison, USA), fragmentation of mRNA, random-primed synthesis of cDNA, double strand synthesis and library preparation. Sequencing was performed using Illumina HiSeq 2000 and 50 bp single read mode resulting in $15,202,000$ to $37,966,600$ quality reads per sample. Reads were mapped to the reference genome of S. rhizophila DSM $14405^{\mathrm{T}}$ and only the corresponding normalized values for the reads that uniquely mapped to each CDS were used to assess the changes in gene transcription. The transcription fold change as the result of the temperature shift was assessed for each CDS by dividing its read number for the cell culture treated at $35^{\circ} \mathrm{C}$ by the value from the culture grown at $30^{\circ} \mathrm{C}$. Of the total genes either up or down-regulated, only those showing fold changes greater than or equal to 1.5 and less than or equal to 0.6 were considered as significantly impacted.

\section{Availability of supporting data}

The genome of Stenotrophomonas rhizophila DSM14405 was deposited in the NCBI database and can be accessed under the BioProject Nr. CP007597.

\section{Additional files}

Additional file 1: Figure S1. Genome-scale comparison between the three strains using Artemis Comparison Tool (ACT).

Additional file 2: Table S1. The list of the 884 S. rhizophila DSM $14405^{\top}$ specific genes that are absent from S. maltophilia K279a.

Additional file 3: Table S2. The list of the 1230 S. maltophilia K279a specific genes that are absent from S. rhizophila DSM14405 ${ }^{\top}$.

\section{Competing interests}

The authors declare that they have no competing interests.

\section{Authors' contributions}

PA carried out comparative genomics, bioinformatic and transcriptomic data analysis, figure and table preparation, and drafted the manuscript. MRS conducted preliminary experiments and edited the manuscript. GGT performed the genome sequencing, assembly and annotation. CZ carried out the lab experiments related to transcriptomic studies and RNA extraction. HM and GB participated in the design of the study and revised it carefully for intellectual content. All authors read and approved the final manuscript.

\section{Acknowledgements}

This study was supported by the Austrian Science Foundation FWF (P 20542-B16) by a grant to G.B. The genome sequence was prepared by the Schloter group (Munich); we thank Brigitte Hai and Michael Schoter for excellent cooperation. The genome sequence was funded by a project in the Austrian Centre of Industrial Biotechnology, which has been supported by the Austrian BMWFJ, BMVIT, SFG, Standortagentur Tirol and ZIT through the Austrian FFG-COMET-Funding Program.

\section{Author details}

${ }^{1}$ Graz University of Technology; Environmental Biotechnology, Petersgasse 12, 8010 Graz, Austria. ${ }^{2}$ Institute for Genomics and Bioinformatics, Graz University of Technology, Graz, Austria.

Received: 17 September 2013 Accepted: 11 June 2014 Published: 18 June 2014

\section{References}

1. Hartmann A, Rothballer M, Schmid M: Lorenz Hiltner, a pioneer in rhizosphere microbial ecology and soil bacteriology research. Plant and Soil 2008, 312(1-2):7-14.

2. Berg G, Eberl L, Hartmann A: The rhizosphere as a reservoir for opportunistic human pathogenic bacteria. Environ Microbio/ 2005 , 7(11):1673-1685. 
3. Mendes R, Garbeva P, Raaijmakers JM: The rhizosphere microbiome: significance of plant beneficial, plant pathogenic, and human pathogenic microorganisms. FEMS Microbiol Rev 2013, 37(5):634-663.

4. Berg G, Roskot N, Smalla K: Genotypic and phenotypic relationships between clinical and environmental isolates of Stenotrophomonas maltophilia. J Clin Microbiol 1999, 37(11):3594-3600.

5. Martinez JL: Bacterial pathogens: from natural ecosystems to human hosts. Environ Microbiol 2013, 15(2):325-333.

6. Berg G, Egamberdieva D, Lugtenberg B, Hagemann M: Symbiotic plantmicrobe interactions: stress protection, plant growth promotion, and biocontrol by Stenotrophomonas. In Symbioses and Stress. Netherlands: Anonymous Springer; 2010:445-460.

7. Hirsch PR, Mauchline TH: Who's who in the plant root microbiome? Nat Biotechnol 2012, 30(10):961-962.

8. Ryan RP, Monchy S, Cardinale M, Taghavi S, Crossman L, Avison MB, Berg G, van der Lelie D, Dow JM: The versatility and adaptation of bacteria from the genus Stenotrophomonas. Nat Rev Microbio/ 2009, 7(7):514-525.

9. Brooke JS: Stenotrophomonas maltophilia: an emerging global opportunistic pathogen. Clin Microbiol Rev 2012, 25(1):2-41.

10. Sanchez MB, Hernandez A, Martinez JL: Stenotrophomonas maltophilia drug resistance. Future Microbiol 2009, 4(6):655-660.

11. Wolf A, Fritze A, Hagemann M, Berg G: Stenotrophomonas rhizophila sp. nov., a novel plant-associated bacterium with antifungal properties. Int J Syst Evol Microbiol 2002, 52(Pt 6):1937-1944.

12. Ribbeck-Busch K, Roder A, Hasse D, de Boer W, Martinez JL, Hagemann M, Berg G: A molecular biological protocol to distinguish potentially human pathogenic Stenotrophomonas maltophilia from plant-associated Stenotrophomonas rhizophila. Environ Microbiol 2005, 7(11):1853-1858.

13. Berg G, Alavi P, Schmidt C, Egamberdieva D, Kamilova F, Lugtenberg B: In Molecular Microbial Ecology of the Rhizosphere. Volume 2. 1st edition. Edited by de Bruijn FJ. Oxford, UK: Wiley-Blackwell; 2013.

14. Schmidt CS, Alavi M, Cardinale M, Müller H, Berg G: Stenotrophomonas rhizophila DSM14405T promotes plant growth probably by altering fungal communities in the rhizosphere. Biol Fertility Soils 2012, 48(8):947-960

15. Egamberdieva D, Kucharova Z, Davranov K, Berg G, Makarova N, Azarova T, Chebotar V, Tikhonovich I, Kamilova F, Validov SZ: Bacteria able to control foot and root rot and to promote growth of cucumber in salinated soils. Biol Fertility Soils 2011, 47(2):197-205.

16. Berg G: Plant-microbe interactions promoting plant growth and health: perspectives for controlled use of microorganisms in agriculture. Appl Microbiol Biotechnol 2009, 84(1):11-18.

17. Ehlers R: Regulation of Biological Control Agents. Dordrecht, Heidelberg, London, New York: Springer Science+Business Media; 2011:417.

18. Schenk PM, Carvalhais LC, Kazan K: Unraveling plant-microbe interactions: can multi-species transcriptomics help? Trends Biotechnol 2012, 30(3):177-184

19. Köberl M, Schmidt R, Ramadan EM, Bragina A, Müller H, Berg G: Biocontrol Strategies and Next Generation Sequencing: Organic Desert Agriculture in Egypt. Brisbane, Australia: iConcept Press; 2013

20. Crossman LC, Gould VC, Dow JM, Vernikos GS, Okazaki A, Sebaihia M, Saunders D, Arrowsmith C, Carver T, Peters N, Adlem E, Kerhornou A, Lord A, Murphy L, Seeger K, Squares R, Rutter S, Quail MA, Rajandream MA, Harris D, Churcher C, Bentley SD, Parkhill J, Thomson NR, Avison MB: The complete genome, comparative and functional analysis of Stenotrophomonas maltophilia reveals an organism heavily shielded by drug resistance determinants. Genome Biol 2008, 9(4):R74-2008-9-4-r74.

21. Taghavi S, Garafola C, Monchy S, Newman L, Hoffman A, Weyens N, Barac T, Vangronsveld J, van der Lelie D: Genome survey and characterization of endophytic bacteria exhibiting a beneficial effect on growth and development of poplar trees. Appl Environ Microbiol 2009, 75(3):748-757.

22. Barber CE, Tang JL, Feng JX, Pan MQ, Wilson TJ, Slater H, Dow JM, Williams $P$, Daniels MJ: A novel regulatory system required for pathogenicity of Xanthomonas campestris is mediated by a small diffusible signal molecule. Mol Microbiol 1997, 24(3):555-566

23. Wang LH, He Y, Gao Y, Wu JE, Dong YH, He C, Wang SX, Weng LX, Xu JL, Tay L, Fang RX, Zhang LH: A bacterial cell-cell communication signal with cross-kingdom structural analogues. Mol Microbiol 2004, 51(3):903-912.

24. Deng Y, Wu J, Tao F, Zhang LH: Listening to a new language: DSF-based quorum sensing in Gram-negative bacteria. Chem Rev 2011, 111(1):160-173.
25. Ryan RP, Dow JM: Communication with a growing family: diffusible signal factor (DSF) signaling in bacteria. Trends Microbio/ 2011, 19(3):145-152.

26. Slater H, Alvarez-Morales A, Barber CE, Daniels MJ, Dow JM: A twocomponent system involving an HD-GYP domain protein links cell-cell signalling to pathogenicity gene expression in Xanthomonas campestris. Mol Microbiol 2000, 38(5):986-1003.

27. Fouhy Y, Scanlon K, Schouest K, Spillane C, Crossman L, Avison MB, Ryan RP, Dow JM: Diffusible signal factor-dependent cell-cell signaling and virulence in the nosocomial pathogen Stenotrophomonas maltophilia. J Bacteriol 2007, 189(13):4964-4968.

28. Pratt LA, Kolter R: Genetic analysis of Escherichia coli biofilm formation: roles of flagella, motility, chemotaxis and type I pili. Mol Microbio/ 1998, 30(2):285-293.

29. Vande Broek A, Lambrecht M, Vanderleyden J: Bacterial chemotactic motility is important for the initiation of wheat root colonization by Azospirillum brasilense. Microbiology 1998, 144(Pt 9):2599-2606.

30. de Weert S, Vermeiren H, Mulders IH, Kuiper I, Hendrickx N, Bloemberg GV, Vanderleyden J, De Mot R, Lugtenberg BJ: Flagella-driven chemotaxis towards exudate components is an important trait for tomato root colonization by Pseudomonas fluorescens. Mol Plant Microbe Interact 2002, 15(11):1173-1180.

31. Minkwitz A, Berg G: Comparison of antifungal activities and 16S ribosomal DNA sequences of clinical and environmental isolates of Stenotrophomonas maltophilia. J Clin Microbiol 2001, 39(1):139-145.

32. Roder A, Hoffmann E, Hagemann M, Berg G: Synthesis of the compatible solutes glucosylglycerol and trehalose by salt-stressed cells of Stenotrophomonas strains. FEMS Microbiol Lett 2005, 243(1):219-226.

33. Huang TP, Somers EB, Wong AC: Differential biofilm formation and motility associated with lipopolysaccharide/exopolysaccharide-coupled biosynthetic genes in Stenotrophomonas maltophilia. J Bacteriol 2006, 188(8):3116-3120.

34. Smith HE, Damman M, van der Velde J, Wagenaar F, Wisselink HJ, Stockhofe-Zurwieden N, Smits MA: Identification and characterization of the cps locus of Streptococcus suis serotype 2: the capsule protects against phagocytosis and is an important virulence factor. Infect Immun 1999, 67(4):1750-1756.

35. Boyce JD, Adler $B$ : The capsule is a virulence determinant in the pathogenesis of Pasteurella multocida M1404 (B:2). Infect Immun 2000, 68(6):3463-3468.

36. Reckseidler SL, DeShazer D, Sokol PA, Woods DE: Detection of bacterial virulence genes by subtractive hybridization: identification of capsular polysaccharide of Burkholderia pseudomallei as a major virulence determinant. Infect Immun 2001, 69(1):34-44.

37. Cuccui J, Milne TS, Harmer N, George AJ, Harding SV, Dean RE, Scott AE, Sarkar-Tyson M, Wren BW, Titball RW, Prior JL: Characterization of the Burkholderia pseudomallei K96243 capsular polysaccharide I coding region. Infect Immun 2012, 80(3):1209-1221.

38. Monday SR, Schiller NL: Alginate synthesis in Pseudomonas aeruginosa: the role of AlgL (alginate lyase) and AlgX. J Bacteriol 1996, 178(3):625-632.

39. Lyczak JB, Cannon CL, Pier GB: Lung infections associated with cystic fibrosis. Clin Microbiol Rev 2002, 15(2):194-222.

40. Stapper AP, Narasimhan G, Ohman DE, Barakat J, Hentzer M, Molin S, Kharazmi A, Hoiby N, Mathee K: Alginate production affects Pseudomonas aeruginosa biofilm development and architecture, but is not essential for biofilm formation. J Med Microbio/ 2004, 53(Pt 7):679-690.

41. Al-Whaibi MH, Siddiqui MH, Al-Munqadhi BM, Sakran AM, Ali HM, Basalah $\mathrm{MO}$ : Influence of plant growth regulators on growth performance and photosynthetic pigments status of Eruca sativa Mill. J Med Plants Res 2012, 6(10):1948-1954

42. Alavi P, Starcher MR, Zachow C, Muller H, Berg G: Root-microbe systems: the effect and mode of interaction of Stress Protecting Agent (SPA) Stenotrophomonas rhizophila DSM14405 (T.). Front Plant Sci 2013, 4:141.

43. Hyatt D, Chen GL, Locascio PF, Land ML, Larimer FW, Hauser LJ: Prodigal: prokaryotic gene recognition and translation initiation site identification. BMC Bioinformatics 2010, 11:119-2105-11-119.

44. Laslett D, Canback B: ARAGORN, a program to detect tRNA genes and tmRNA genes in nucleotide sequences. Nucleic Acids Res 2004, 32(1):11-16.

45. Lagesen K, Hallin P, Rodland EA, Staerfeldt HH, Rognes T, Ussery DW: RNAmmer: consistent and rapid annotation of ribosomal RNA genes. Nucleic Acids Res 2007, 35(9):3100-3108 
46. Van Domselaar GH, Stothard P, Shrivastava S, Cruz JA, Guo A, Dong X, Lu P, Szafron D, Greiner R, Wishart DS: BASys: a web server for automated bacterial genome annotation. Nucleic Acids Res 2005, 33(Web Server issue):W455-9.

47. Tatusov RL, Fedorova ND, Jackson JD, Jacobs AR, Kiryutin B, Koonin EV, Krylov DM, Mazumder R, Mekhedov SL, Nikolskaya AN, Rao BS, Smirnov S, Sverdlov AV, Vasudevan S, Wolf YI, Yin JJ, Natale DA: The COG database: an updated version includes eukaryotes. BMC Bioinformatics 2003, 4:41

48. Finn RD, Mistry J, Tate J, Coggill P, Heger A, Pollington JE, Gavin OL, Gunasekaran P, Ceric G, Forslund K, Holm L, Sonnhammer EL, Eddy SR, Bateman A: The Pfam protein family's database. Nucleic Acids Res 2010, 38(Database issue):D211-D222.

49. Gene Ontology Consortium: Creating the gene ontology resource: design and implementation. Genome Res 2001, 11(8):1425-1433.

50. Darling AE, Mau B, Perna NT: ProgressiveMauve: multiple genome alignment with gene gain, loss and rearrangement. PLOS One 2010, 5(6):e11147.

51. Carver TJ, Rutherford KM, Berriman M, Rajandream MA, Barrell BG, Parkhill J: ACT: the Artemis Comparison Tool. Bioinformatics 2005, 21(16):3422-3423.

52. Carver T, Thomson N, Bleasby A, Berriman M, Parkhill J: DNAPlotter: circular and linear interactive genome visualization. Bioinformatics 2009, 25(1):119-120.

doi:10.1186/1471-2164-15-482

Cite this article as: Alavi et al: Stenotrophomonas comparative genomics reveals genes and functions that differentiate beneficial and pathogenic bacteria. BMC Genomics 2014 15:482.

\section{Submit your next manuscript to BioMed Central and take full advantage of:}

- Convenient online submission

- Thorough peer review

- No space constraints or color figure charges

- Immediate publication on acceptance

- Inclusion in PubMed, CAS, Scopus and Google Scholar

- Research which is freely available for redistribution 